\title{
Oviposition preference and reproductive performance of Japanese Helicoverpa armigera (Hübner) (Lepidoptera: Noctuidae)
}

\author{
Mustapha F. A. Jallow, ${ }^{1}$ Masaya Matsumura and Yoshito Suzuki ${ }^{2}$ \\ Laboratory of Pest Management Systems, National Agricultural Research Center for Kyushu Okinawa Region, Nishigoshi, \\ Kumamoto 861-1192, Japan \\ (Received 27 November 2000; Accepted 18 June 2001)
}

\begin{abstract}
We investigated the host selection behavior and reproductive performance of Helicoverpa armigera (Hübner) in glasshouse bioassays. Irrespective of the growth stages of the host species tested, females showed strong oviposition preference for maize and okra, followed by tomato. There was a distinct non-preference for eggplant and pepper. The preferred ovipositional site on tomato, maize, okra and pepper was on leaves, and on eggplant, flowers and fruits were more preferred. The within-plant distribution of larvae based on the number of larvae feeding per plant part was highest on flowers and fruits of tomato and on the silk, cob and tassel of maize. Leaves were the preferred feeding sites for neonates on okra. Bionomics studies indicated a significant variation in the ability of different host plants to support the life history stages of the insect. Larvae reared on maize and okra had low survival rates, and produced smaller pupae that were more likely to die, and emerged adults were less fecund compared to those reared on tomato, eggplant, pepper and artificial diet. These results suggest that for $H$. armigera, growth and survival of offspring appear unrelated to adult host plant choice.
\end{abstract}

Key words: Helicoverpa armigera, host plants, oviposition behaviour, reproductive performance

\section{INTRODUCTION}

Helicoverpa armigera (Hübner) is an important economic insect pest in many parts of the world (Zalucki et al., 1986, 1994; Fitt, 1989). The species is highly polyphagous, and this is reflected in the wide taxonomic range of wild and cultivated plants acceptable for oviposition by adults and feeding by larvae (Zalucki et al., 1986, 1994; King, 1994). The polyphagous nature of $H$. armigera is one of the major factors contributing to the pest status of this moth (Fitt, 1989). The occurrence of $H$. armigera in Japan has long been recorded, but field population densities were generally low until outbreaks were observed in western Japan in 1994 (Yoshimatsu, 1995). Important agricultural crops such as green peas, chrysanthemum, tomato, okra, cabbage, carrot, lettuce, eggplants, and pepper are among the host records of $H$. armigera in Japan (Yoshimatsu, 1995; Hamamura, 1998).

Whereas the ecology and basic biology of the species, especially host-related behaviours, are elucidated in other regions, not much is known about
Japanese $H$. armigera. Understanding the host selection behavior and the effects of various host species on development and reproduction of $H$. armigera is an important prerequisite for developing pest management strategies for this insect. In the present study, therefore, we investigated Japanese $H$. armigera strains for information on oviposition behavior and reproductive performance. Our first objective was to determine both the physical and chemical plant attributes that may influence oviposition behavior, and whether female moths exhibit an oviposition preference hierarchy in response to different host plant species. The second was to determine the preferred oviposition site, within-plant distribution of larvae, and the suitability of various host species to support the development, survival and fecundity of $H$. armigera.

\section{MATERIALS AND METHODS}

Insect and rearing procedures. Insects were field-collected $H$. armigera larvae from different host plants, provided by the Kumamoto Prefectural

\footnotetext{
${ }^{1}$ Present address: Institute for Plant Pathology and Plant Protection, Georg-August-University, Grisebachstr. 6, D-37077 Goettingen, Germany

${ }^{2}$ Present address: National Agricultural Research Center, Tsukuba, Ibaraki 305-8666, Japan
} 
Agricultural Research Center. The larvae were reared on a commercially formulated artificial diet (Insecta LF, Nihon-Nosan Kogyo Co.) to minimize the influence of host plant experience on oviposition (Cunningham et al., 1998). First and second instars were reared collectively in $570 \mathrm{ml}$ plastic containers and third instars were held individually in plastic containers $(28 \mathrm{ml})$ until pupation to prevent cannibalism (Twine, 1971). Pupae were sexed and transferred into a clear container lined with filter paper for adult emergence. The adult moths emerged directly into a mating cage $(40 \mathrm{~cm} \times$ $25 \mathrm{~cm} \times 25 \mathrm{~cm})$, provided with $10 \%(\mathrm{w} / \mathrm{v})$ sugar solution, and held for 3 days after eclosion to allow mating and egg maturation (Jallow and Zalucki, 1998). The culture was maintained at a constant temperature of $25( \pm 1)^{\circ} \mathrm{C}$, relative humidity of $75 \%$ and a photoperiod of $12 \mathrm{~L}: 12 \mathrm{D}$.

Host plants. We selected various hosts of $H$. armigera: maize, Zea mays (L.); tomato, Lycopersicon esculentum (L.); okra, Hibiscus esculentus; eggplant, Solanum melongena (L.); and pepper, Capsicum annum (L.) as experimental plants. All test plants except maize were raised in a nursery and later transplanted as seedlings into $50 \mathrm{~cm}$ pots (1 plant/pot) in a potting mixture (50-50 sand: peat, mixed with $100 \mathrm{~g}$ of fertilizer per $40-l$ of mixture). Maize seeds were sown directly into the pots, and were thinned down to 1 plant per pot two weeks after planting. Planting was scheduled to generate a continuous supply of flowering and pre-flowering plants that were maintained in a glasshouse at $25 \pm 4{ }^{\circ} \mathrm{C}$ and $75 \pm 3 \%$ relative humidity. Conditions in all glasshouse experiments conducted in this study were similar to those described for growing plants.

Oviposition preference. The rank order of host plant preference was evaluated in a glasshouse $(5 \mathrm{~m} \times 5 \mathrm{~m} \times 3 \mathrm{~m})$ using potted flowering plants, each host species replicated three times in a randomized complete block design. The plants were placed such that the fringes of each species were at least $20 \mathrm{~cm}$ from adjacent species, and were raised to the same height to minimize any effects of plant height on oviposition (Firempong and Zalucki, 1990a). Sterile cotton balls saturated with $10 \%$ honey solution were placed in $15 \mathrm{~cm}$ plastic containers, and suspended at different positions in the glasshouse to serve as feeding sites for the moths. Oviposition behavior in $H$. armigera commenced at dusk (Zalucki et al., 1986; King, 1994). Thus, 30 mated females were released into the glasshouse at $19.00 \mathrm{~h}$ prior to the onset of the scotophase; the following morning eggs deposited on each plant were counted, recorded, and removed to avoid counting them more than once. The experiment ran for four nights, and was repeated four times using new batches of moths and plants. We conducted a second experiment; the experimental procedures were the same as those for the first assay using flowering plants, except that the moths were offered pre-flowering plants.

In a separate bioassay, glasshouse tests were conducted to determine the preferred oviposition sites of $H$. armigera. A single flowering host species was offered to female moths (no-choice tests), so that selection was of parts of the plant on which eggs were laid. Each treatment consisted of six replicates (six potted plants of the same host species). Ten mated females were released into the glasshouse at $19.00 \mathrm{~h}$ and after $36 \mathrm{~h}$, eggs deposited on different plant structures were counted.

Within-plant distribution of larvae. A randomized complete block design using flowering tomato, okra and maize, each replicated three times, was set up in a glasshouse $(5 \mathrm{~m} \times 5 \mathrm{~m} \times 3 \mathrm{~m})$. The potted plants were raised to the same height, and care was taken to avoid contact between plant terminals. Twenty mated females were released into the glasshouse at $19.00 \mathrm{~h}$, and after being allowed to oviposit for two nights, the moths were removed from the glasshouse. The plants were visually inspected for larvae 4, 8 and 12 days following oviposition. For each larva found, the approximate stadium (determined by head-capsule size and color) of the larva and the plant part on which it was found feeding were recorded.

Larval establishment and reproductive performance. To determine the effects of host plant species on $H$. armigera establishment, survival and development, we infested each plant species (2 potted plants/species) with 80 first stadium larvae. The larvae were placed randomly on the upper third of the plants, the major oviposition site for female moths (this study). Tests were conducted on flowering plants in a glasshouse, each plant species replicated three times in a randomized complete block design. The plants were placed such that the fringes of each species were at least $20 \mathrm{~cm}$ from adjacent plants, and were raised to the same height. 
Larval survival was recorded by daily inspection of individual plants until all larvae had died or reached the final stadium (determined by head-capsule size and color). Surviving larvae were transferred individually into clean dry plastic containers, labelled and kept in an environment-controlled growth chamber for pupation under conditions similar to the glasshouse. Newly formed pupae were sexed, and weighed using an electronic balance to the nearest $0.1 \mathrm{mg}$ within $24 \mathrm{~h}$ of pupation.

Newly emerged adults $\left(\mathrm{F}_{1}\right)(5$ male-female pairs from each test plant species) were kept separately in oviposition cages, and fed on $10 \%$ honey solution. Eggs were collected and counted each morning for 5 days. Larvae from plant treatments were compared with control larvae reared on artificial diet in the laboratory. The following parameters were used to determine the suitability of the test plants: larval establishment (survival to second stadium), larval period (days from first stadium to pupation), pupal period (days from pupation to adult emergence), larval survival to pupation, pupal survival and weight, and female fecundity (number of eggs laid over 5 days).

Data analysis. An analysis of variance (ANOVA) was conducted to determine the significance of differences between means using StatView $^{\circledR} 4.0$ (Haycock et al., 1992), and means were compared using Fisher's LSD mean separation (Steel and Torrie, 1980). Because of the inherent variability in egg production among females, eggs laid on different host species were converted to percentages of the total number of eggs laid on all host species. Percentage egg data were arcsinetransformed to correct heterogeneity of variances prior to analysis.

\section{RESULTS}

\section{Oviposition preference}

Irrespective of the growth stages of the host species, $H$. armigera showed strong oviposition preference for maize and okra, followed by tomato. There was a distinct non-preference for eggplant and pepper (Fig. 1). Among the highly preferred host species, flowering maize received a significantly $(p<0.05)$ greater number of eggs than flowering okra (Fig. 1A), but no differences were observed when females were offered pre-flowering plants (Fig. 1B). There was no significant differ-
(A)

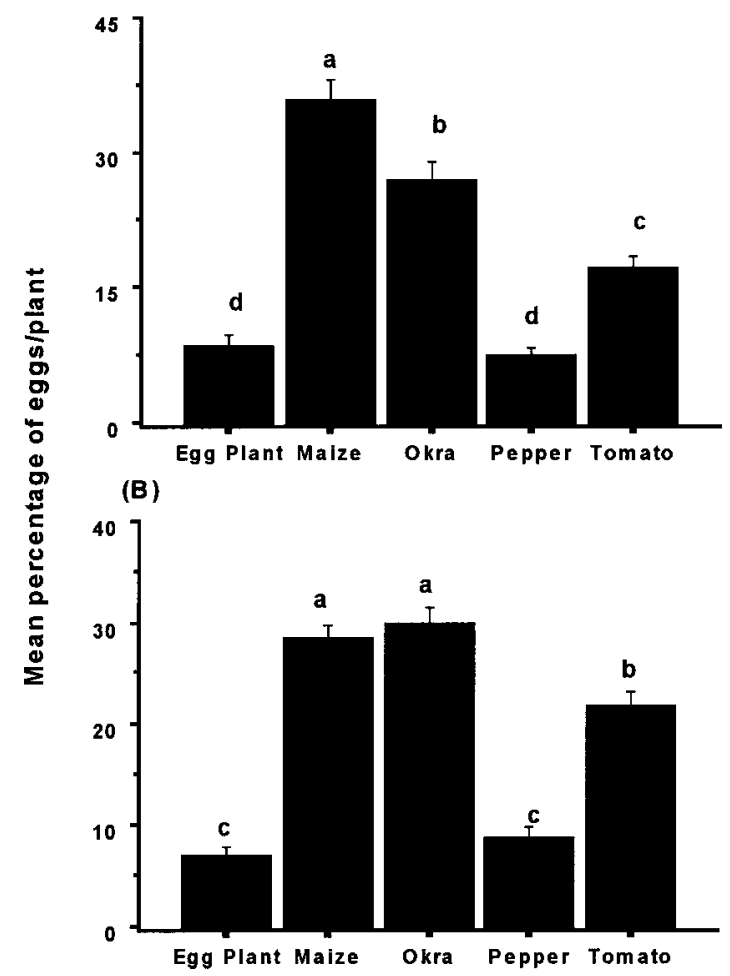

Fig. 1. Oviposition preference of $H$. armigera for (A) flowering and (B) pre-flowering host plant species (mean \pm $\mathrm{SE}$ ). Histogram bars with different letters indicate significantly different means ( $p<0.05$, Fisher's LSD mean separation).

ence $(p>0.05)$ in egg number between eggplant and pepper for both flowering and pre-flowering stages of the host plants (Fig. 1). The preferred ovipositional site on okra, tomato, pepper and maize was the foliage compared to other plant parts, with the upper leaf surface of maize receiving significantly $(p<0.05)$ more eggs than the lower leaf surface (Table 1). Moths demonstrated a significant $(p<0.05)$ preference for flowers and fruits compared to the foliage on eggplant (Table 1).

\section{Within-plant distribution of larvae}

The distribution of larvae found feeding on different plant structures of tomato changed with the larval stage. A significantly $(p<0.05)$ greater number of larvae (first and second instars) was found feeding on tomato leaves compared to other plant structures 4 days following oviposition (Fig. 2A). Eight and 12 days following oviposition, more larvae (third to final instars) were located feeding on tomato flowers compared to tomato leaves (Fig. 
Table 1. Mean percentage of H. armigera eggs deposited on plant structures of different host species

\begin{tabular}{|c|c|c|c|c|c|}
\hline \multirow{2}{*}{ Oviposition site } & \multicolumn{5}{|c|}{ Eggs deposited (mean \pm SE) } \\
\hline & Okra & Tomato & Eggplant & Pepper & Maize \\
\hline Stem & $4.52 \pm 0.98 \mathrm{~d}$ & $5.63 \pm 1.06 \mathrm{c}$ & $4.44 \pm 0.10 \mathrm{~d}$ & $1.52 \pm 0.01 \mathrm{c}$ & $0.52 \pm 0.01 \mathrm{~d}$ \\
\hline Leaf surface, lower & $26.64 \pm 4.12 \mathrm{ab}$ & $27.80 \pm 3.21 \mathrm{a}$ & $12.63 \pm 3.92 \mathrm{c}$ & $25.18 \pm 5.41 \mathrm{ab}$ & $22.72 \pm 2.41 \mathrm{~b}$ \\
\hline Leaf surface, upper & $29.14 \pm 3.16 \mathrm{a}$ & $35.73 \pm 6.23 \mathrm{a}$ & $21.83 \pm 4.95 b$ & $35.15 \pm 4.90 \mathrm{a}$ & $35.82 \pm 5.29 \mathrm{a}$ \\
\hline Flower & $22.26 \pm 2.98 b c$ & $17.42 \pm 3.16 b$ & $45.45 \pm 5.11 \mathrm{a}$ & $19.89 \pm 3.10 b$ & $* *$ \\
\hline Fruits & $17.44 \pm 4.21 \mathrm{c}$ & $13.42 \pm 3.98 b$ & $15.65 \pm 4.98 b c$ & $18.26 \pm 1.91 \mathrm{~b}$ & $* *$ \\
\hline Silk & $* *$ & $* *$ & $* *$ & $* *$ & $16.90 \pm 4.10 \mathrm{bc}$ \\
\hline Tassels & $* *$ & $* *$ & $* *$ & $* *$ & $10.22 \pm 3.90 \mathrm{c}$ \\
\hline Cob & $* *$ & $* *$ & $* *$ & $* *$ & $13.82 \pm 2.91 \mathrm{c}$ \\
\hline
\end{tabular}

Within-column, means followed by the same letter are not significantly different ( $p>0.05$, Fisher's LSD mean separation). Data were arcsine transformed before being subjected to analysis of variance. ** Mean percentage of eggs not measured.

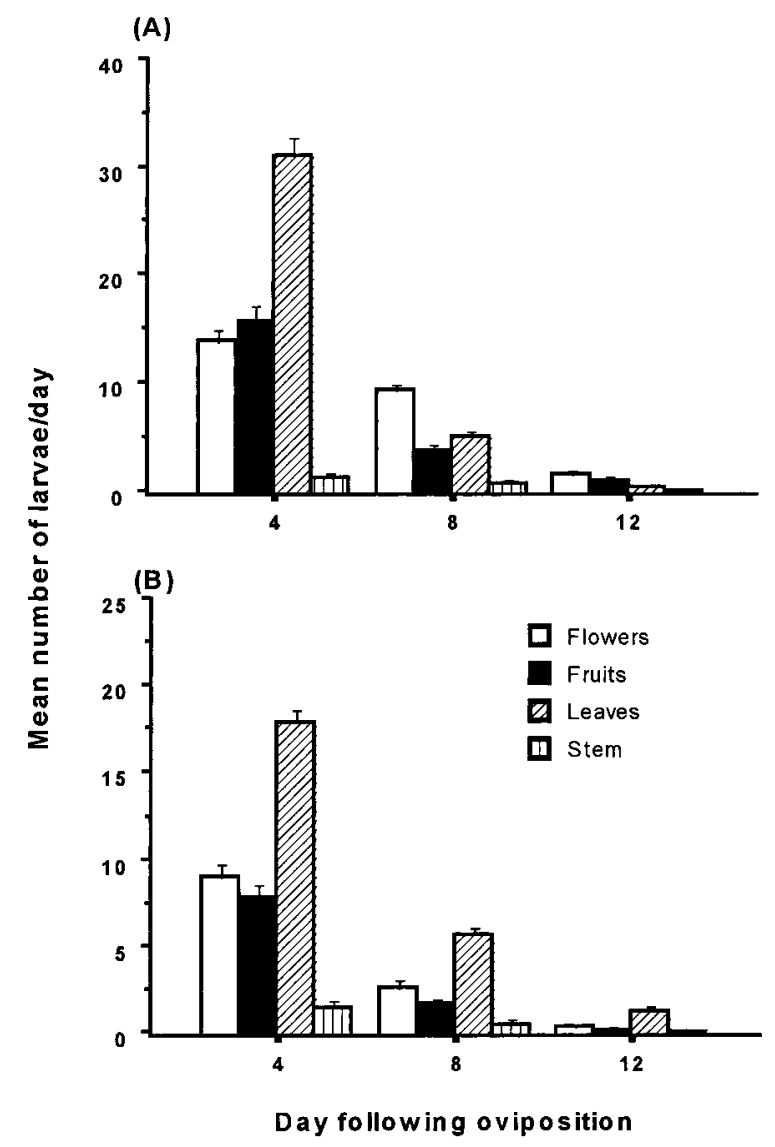

Fig. 2. Within-plant distribution of $H$. armigera larvae on (A) flowering tomato and (B) flowering okra.

2A). On okra, a significantly $(p<0.05)$ greater number of larvae (all instars) was recorded feeding on leaves compared to other plant structures (Fig. 2B). The number of larvae (all stages) found feeding on reproductive structures of maize (cob, silk

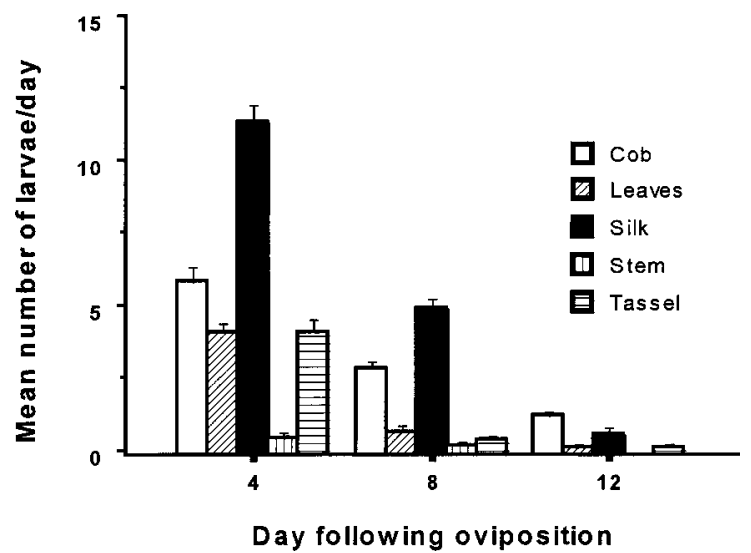

Fig. 3. Within-plant distribution of H. armigera larvae on flowering maize.

and tassel) was significantly greater $(p<0.05)$ compared to that on leaves (Fig. 3).

\section{Larval establishment and reproductive perform- ance}

There was a significant $(p<0.05)$ effect of host plant species on larval establishment (survival to second stadium) and overall larval and pupal survival (Table 2). Larval establishment was low on all host species tested, with the lowest establishment recorded on maize and okra. Although the percentage larval establishment on eggplant, pepper and tomato did not differ, significantly $(p<0.05)$ more larvae survived on eggplant and pepper than on tomato (Table 2). Percentage larval survival was significantly $(p<0.05)$ lower on maize and okra compared to the other host species (Table 2). Significantly $(p<0.05)$ more pupae survived on artifi- 
Table 2. Larval establishment and survival, pupal survival, pre-oviposition period and fecundity of H. armigera reared on different host species and artificial diet ${ }^{\mathrm{a}}$

\begin{tabular}{lccccc}
\hline Reared on & $\begin{array}{c}\text { \% larval } \\
\text { establishment } \\
(\text { mean } \pm \mathrm{SE})^{\mathrm{b}}\end{array}$ & $\begin{array}{c}\text { \% larval } \\
\text { survival } \\
(\text { mean } \pm \mathrm{SE})^{\mathrm{c}}\end{array}$ & $\begin{array}{c}\text { \% pupal } \\
\text { survival } \\
(\text { mean } \pm \mathrm{SE})\end{array}$ & $\begin{array}{c}\text { Pre-oviposition } \\
\text { period (days) } \\
(\text { mean } \pm \mathrm{SE})\end{array}$ & $\begin{array}{c}\text { Fecundity/female } \\
(\mathrm{mean} \pm \mathrm{SE})\end{array}$ \\
\hline Artificial diet & $81.25 \pm 3.91 \mathrm{a}$ & $74.43 \pm 4.71 \mathrm{a}$ & $71.76 \pm 4.67 \mathrm{a}$ & $2.68 \pm 0.15 \mathrm{~b}$ & $742.95 \pm 22.10 \mathrm{a}$ \\
Eggplant & $61.28 \pm 3.87 \mathrm{~b}$ & $54.13 \pm 3.01 \mathrm{~b}$ & $42.49 \pm 2.37 \mathrm{~b}$ & $2.72 \pm 0.01 \mathrm{~b}$ & $568.23 \pm 19.49 \mathrm{c}$ \\
Pepper & $52.45 \pm 5.21 \mathrm{~b}$ & $48.58 \pm 2.83 \mathrm{~b}$ & $36.65 \pm 1.62 \mathrm{c}$ & $3.29 \pm 0.19 \mathrm{a}$ & $424.21 \pm 16.12 \mathrm{~d}$ \\
Maize & $35.21 \pm 2.80 \mathrm{c}$ & $29.89 \pm 1.28 \mathrm{~d}$ & $19.94 \pm 0.91 \mathrm{~d}$ & $3.21 \pm 0.21 \mathrm{a}$ & $285.01 \pm 32.98 \mathrm{e}$ \\
Okra & $42.18 \pm 3.28 \mathrm{~d}$ & $32.46 \pm 1.38 \mathrm{~d}$ & $21.23 \pm 0.23 \mathrm{~d}$ & $3.27 \pm 0.14 \mathrm{a}$ & $394.98 \pm 19.10 \mathrm{~d}$ \\
Tomato & $57.91 \pm 3.21 \mathrm{~b}$ & $41.25 \pm 2.45 \mathrm{c}$ & $34.94 \pm 2.33 \mathrm{c}$ & $3.10 \pm 0.01 \mathrm{a}$ & $642.21 \pm 32.12 \mathrm{~b}$ \\
\hline
\end{tabular}

Within-column, means followed by the same letter are not significantly different ( $p>0.05$, Fisher's LSD mean separation). Data were arcsine transformed before being subjected to analysis of variance.

${ }^{a}$ First stadium larvae reared on each host plant species or artificial diet $=240$.

${ }^{\mathrm{b}}$ Percentage larvae that survived to the third stadium stage.

${ }^{\mathrm{c}}$ Percentage of second stadium larvae surviving to the pupal stage.

Table 3. Pupal weight, larval and pupal duration, and developmental rate of $H$. armigera reared on different host species and artificial diet ${ }^{\mathrm{a}}$

\begin{tabular}{lcccc}
\hline Reared on & $\begin{array}{c}\text { Larval duration (days) } \\
(\text { mean } \pm \text { SE) }\end{array}$ & $\begin{array}{c}\text { Pupal duration (days) } \\
(\text { mean } \pm \text { SE) }\end{array}$ & $\begin{array}{c}\text { Pupal weight }(\mathrm{g}) \\
\text { (mean } \pm \text { SE) }\end{array}$ & $\begin{array}{c}\text { Development rate } \\
\text { b }\end{array}$ \\
\hline Artificial diet & $12.20 \pm 0.40 \mathrm{~d}$ & $13.31 \pm 0.21 \mathrm{~b}$ & $0.33 \pm 0.01 \mathrm{a}$ & $0.0392 \mathrm{a}$ \\
Eggplant & $19.85 \pm 0.24 \mathrm{a}$ & $14.01 \pm 0.30 \mathrm{a}$ & $0.27 \pm 0.02 \mathrm{bc}$ & $0.0295 \mathrm{c}$ \\
Pepper & $20.17 \pm 0.47 \mathrm{a}$ & $14.26 \pm 0.32 \mathrm{a}$ & $0.29 \pm 0.02 \mathrm{bc}$ & $0.0290 \mathrm{c}$ \\
Maize & $14.50 \pm 0.30 \mathrm{c}$ & $14.19 \pm 0.20 \mathrm{a}$ & $0.21 \pm 0.01 \mathrm{~d}$ & $0.0348 \mathrm{~b}$ \\
Okra & $14.76 \pm 0.38 \mathrm{c}$ & $14.13 \pm 0.23 \mathrm{a}$ & $0.25 \pm 0.01 \mathrm{c}$ & $0.0346 \mathrm{~b}$ \\
Tomato & $16.20 \pm 0.45 \mathrm{~b}$ & $13.46 \pm 0.12 \mathrm{~b}$ & $0.31 \pm 0.02 \mathrm{ab}$ & $0.0337 \mathrm{~b}$ \\
\hline
\end{tabular}

Within-column, means followed by the same letter are not significantly different ( $p>0.05$, Fisher's LSD mean separation). Data were arcsine transformed before being subjected to analysis of variance.

${ }^{\text {a }}$ First stadium larvae reared on each host plant species or artificial diet $=240$.

${ }^{b}$ Developmental rate calculated by the reciprocal of the number of total days of larval and pupal periods.

cial diet, and the highest pupal mortality was recorded on maize and okra (Table 2). Pupal mortality on pepper and tomato did not differ significantly. Mean pre-oviposition periods were significantly $(p<0.05)$ shorter for females reared on artificial diet and eggplant compared to females reared on the other host plant species (Table 2). Similarly, females reared on artificial diet had a significantly $(p<0.05)$ higher reproductive output (total egg number) than females reared on the other host plant species (Table 2). Among the host plant species, female fecundity was highest on tomato and lowest on maize (Table 2).

Mean larval duration ranged from $12.20( \pm 0.40)$ days and $20.17( \pm 0.47)$ days for larvae reared on artificial diet and pepper, respectively (Table 3).
Mean larval duration on eggplant and pepper did not differ, and there was no significant difference $(p>0.05)$ between larvae reared on maize and okra. The pupal period was not greatly influenced by the host species on which larvae were reared. This period was not statistically different among eggplant, pepper, maize and okra. However, total development rate was significantly $(p<0.05)$ faster on maize and okra than on eggplant and pepper (Table 3). Larvae reared on artificial diet had significantly $(p<0.05)$ heavier pupal weight than those reared on all host plants except tomato. The lowest pupal weight was recorded on larvae reared on maize (Table 3 ). 


\section{DISCUSSION}

Although $H$. armigera in Japan has been recorded on a wide range of host plant species (Yoshimatsu, 1995; Hamamura, 1998), not all host plants are equally preferred for oviposition (Fig. 1). Female moths displayed preference for particular host species, ranking plants from highly preferred to least preferred. Irrespective of the growth stages of the host species tested, females showed a strong oviposition preference for maize and okra and the least preferred host species were pepper and eggplant. The finding in our study that Japanese $H$. armigera strains exhibit oviposition preference hierarchies is consistent with that reported for the species in other regions (Fenemore and Thanee, 1990; Firempong and Zalucki, 1990b; Ramnath et al., 1992; Jallow and Zalucki, 1995, 1996). Oviposition preference hierarchies in $H$. armigera are known to vary between and within geographic populations (Firempong and Zalucki, 1990b; Jallow and Zalucki, 1996). Therefore, further studies are needed to elucidate whether geographically distant or isolated populations of $H$. armigera in Japan show similar or different preferences for host plants. Information of this type is necessary in tailoring management strategies to different populations that vary in preference characteristics.

The choice of oviposition site may depend partly on the morphological characteristics (trichome density and morphology) and/or chemicals emanating from the surfaces of various plant tissues (Navasero and Ramaswamy, 1991; Udayagiri and Mason, 1995). Female moths are likely to lay more eggs on plant parts with high trichome density and concentration of stimulatory chemicals (Thomson, 1987). In our study most eggs were laid on foliage of maize and tomato, however, fewer larvae especially third to final instars were recorded on these plant parts (Figs. 2A and 3). Mature larvae prefer to feed on reproductive structure of tomato and maize. On okra, larvae were observed to prefer feeding on leaves (Fig. 2A).

Whether larvae hatching from eggs on maize and tomato leaves died in situ or moved to other plant parts was not clarified in our study. However, fewer dead larvae were observed on maize and tomato leaves. It is conceivable that leaves of these two host plants are a poor food source for young larvae because of antifeedant effects and/or low nu- tritive value. This would account for why most larvae that hatched on tomato and maize leaves moved to other feeding sites (e.g. reproductive structures). Therefore, the site of oviposition may be of little importance to immature survival. If the propensity of $H$. armigera larvae to move among feeding sites (leaves to reproductive structures) is important in the field, this could pose serious management problems if treatment decisions are based on population estimates derived from egg counts on leaves. Further studies are necessary to elucidate whether survival of larvae is strongly influenced by the site of oviposition, which determines the site of initial contact with the larvae.

The low larval establishment recorded on all host plant species tested (Table 2) is similar to records obtained in the glasshouse and field by Kyi et al. (1991) working on $H$. armigera. The principal causes of poor establishment of $H$. armigera larvae in the field have been attributed to adverse weather conditions (heavy rainfall, high temperatures and wind) (Wilson et al., 1983), larval incompatibility with host due to physical structures (trichome effects through their ingestion) and allelochemicals (Twine et al., 1983; Van den Berg et al., 1990), predation and parasitism (Evans, 1985). Some of these factors were carefully controlled in the present study, however the effects of host plant were not. This suggests that host plant effects are a major factor influencing larval establishment.

Although the number of test plant species used was limited considering the polyphagous nature of this moth, our study has indicated some significant information regarding the effects of various host plants on $H$. armigera development and reproduction. Most components of performance were positively correlated. Plant species on which survival was low (e.g. maize and okra) produced smaller pupae that were more likely to die, and emerged adults were less fecund (Tables 2 and 3). Nonetheless maize and okra are highly preferred host plants for ovipositing females (Fig. 1). For H. armigera, growth and survival of offspring appear unrelated to adult host plant choice, at least for the host plants tested in our study.

For maize and okra, where larval and pupal mortality, lighter pupal weight and low fecundity are positively correlated, lack of nutrients and effects of allelochemicals (Scriber and Slansky, 1981) or lack of larval ingestion of the plants (Smith, 1992) 
cannot be ruled out as the cause of poor performance. Although $H$. armigera performance on maize and okra is poor, it is not necessarily disadvantageous for adults to invest many eggs on these plants. One advantage offered by maize and okra is faster larval development (Table 3), thus reducing the period of exposure to natural enemies in the field. Duration of the pupal period was not greatly influenced by the diet consumed in the preceding larval stage (Table 3). The survival rate of those pupae, which could successfully emerge into normal adults moths, however, was very much influenced by the type of food consumed by the larvae. The lack of a significant diet effect on pupal period (this study) agrees with earlier findings that there is no apparent effect of larval food and rate of larval growth on duration of the pupal stage of $H$. armigera (Twine, 1978).

Like most generalist feeders, $H$. armigera can utilize a wide range of host plants; however, plants are not equally suitable for adult oviposition, larval survival and development. Among the host plants tested in our study, maize and okra may be classified as poor-quality hosts for $H$. armigera. These findings are in contrast with those of Casimero et al. (2000) working with Japanese $H$. armigera strains. The differences in experimental procedures may partly explain these differences. In our study, larvae were offered whole plants compared to plant parts (okra fruit and corn kernel) used by Casimero et al. (2000). Profound differences in food quality are possible between whole plants and exercised plant parts; consequently, performance of larvae feeding on whole plants may be totally different from those feeding on plant parts. Plants physically damaged by larvae may undergo significant changes in plant chemistry, and these changes may decrease the fitness of insects feeding on them (Bernays and Chapman, 1977). Larvae feeding on whole plants are more likely to be exposed to extreme plant defence mechanisms (e.g. allelochemicals) than larvae feeding on individual plant parts in the laboratory.

The non-significant correlation recorded between oviposition preference and larval performance is consistent with that reported by Fenemore and Thanee (1990) also working on $H$. armigera. One might expect that females would not consistently prefer, as ovipositional host, plants (e.g. maize and okra) that are not suitable for larval de- velopment. Several factors could explain the lack of correlation between adult host selection behavior and offspring performance (for review, see Thompson, 1988). The behavioral patterns that maximize fitness of the parent may not involve preference for the most suitable larval host. The insect may have a wide host range for oviposition, with only few host species suitable for larval survival and development, which seems to occur with H. armigera.

Females accepted all host species tested in our study, suggesting that $H$. armigera show flexibility in their host selection behavior and eggs may be deposited over a wide range of plants. This host selection strategy allows most potential host plants to be exploited, and females spread their reproductive investment (eggs) on both highly preferred and least preferred host species, some of which will negatively covary with offspring fitness, conceivably spreading the risk of immature mortality. $H$. armigera is known to utilize many plant species for oviposition that are not normally accepted by larvae as food (Walter and Benfield, 1994; Zalucki et al., 1994). A considerable potential exists for the manipulation of cropping systems to incorporate diversionary hosts (e.g. using maize a highly preferred host as a trap crop), thus maximizing the difficulty of emerging populations invading valuable crops, and providing refuges for beneficial organisms.

In summary, the results of our study indicate that: (1) variation in the suitability of host plants could substantially explain the observed variation in H. armigera performance; (2) female moths exhibit oviposition preference hierarchies, and appear to select host plants contributing less to their offspring fitness; and (3) within-plant distribution of eggs and larvae should be considered when sampling protocols are developed. However, our study was conducted under controlled conditions in a glasshouse, preventing the evaluation of other ecological factors (e.g. differential predation and host plant density) that can play an important role in the oviposition preference of moths and reproductive performance of their offspring. Therefore, data in this study should be supplemented by similar analyses in the field.

\section{ACKNOWLEDGEMENTS}

We thank Mr. T. Furuie of Kumamoto Prefectural Agricul- 
tural Research Center for providing the insects, and colleagues in the Laboratory of Pest Management Systems for assistance with experiments. The Science and Technology Agency of Japan funded the research.

\section{REFERENCES}

Bernays, E. A. and R. F. Chapman (1977) The importance of chemical inhibition of feeding in host plant selection by Chorthippus parallelus (Zetterstedt). Acrida 4: 83-93.

Casimero, V., R. Tsukuda, F. Nakasuji and K. Fujisaki (2000) Effect of larval diets on the survival and development of larvae in the cotton bollworm, Helicoverpa armigera Hübner (Lepidoptera: Noctuidae). Appl. Entomol. Zool. 35: 69-74.

Cunningham, J. P., M. F. A. Jallow, D. J. Wright and M. P. Zalucki (1998) Learning in host selection in Helicoverpa armigera (Hübner) (Lepidoptera: Noctuidae). Anim. Behav. 55: 227-234.

Evans, M. L. (1985) Arthropod species in soybeans in Southeast Queensland. J. Aust. Entomol. Soc. 24: 169-177.

Fenemore, P. G. and N. Thanee (1990) Oviposition preference and larval food quality in Helicoverpa armigera. Symp. Biol. Hung. 39: 461-462.

Firempong, S. and M. P. Zalucki (1990a) Host plant selection by Helicoverpa armigera (Hübner) (Lepidoptera: Noctuidae): Role of certain plant attributes. Aust. J. Zool. 37: 675-683.

Firempong, S. and M. P. Zalucki (1990b) Host plant preferences of populations of Helicoverpa armigera (Hübner) (Lepidoptera: Noctuidae) from different geographic locations. Aust. J. Zool. 37: 665-673.

Fitt, G. P. (1989) The ecology of Heliothis species in relation to agroecosystems. Annu. Rev. Entomol. 34: 17-52.

Hamamura, T. (1998) Recent occurrence and injury of Helicoverpa armigera - from questionnaire investigation. Plant. Protection 52: 407-413 (in Japanese).

Haycock, K., J. Roth, J. Gagnon, W. F. Finzer and C. Soper (1992) Stat-View ${ }^{\circledR}$ User Manual: The Ultimate Integrated Data Analysis and Presentation System. Abacus Concept, Berkeley.

Jallow, M. F. A. and M. P. Zalucki (1995) A technique for measuring intraspecific variation in oviposition preference in Helicoverpa armigera (Hübner) (Lepidoptera: Noctuidae). J. Aust. Entomol. Soc. 34: 281-288.

Jallow, M. F. A. and M. P. Zalucki (1996) Within- and between-population variation in host-plant preference and specificity in Australian Helicoverpa armigera (Hübner) (Lepidoptera: Noctuidae). Aust. J. Zool. 44: 503-519.

Jallow, M. F. A. and M. P. Zalucki (1998) Effects of egg load on the host-selection behaviour of Helicoverpa armigera (Hübner) (Lepidoptera: Noctuidae). Aust. J. Zool. 46: 291-299.

King, A. B. S. (1994) Heliothis/Helicoverpa (Lepidoptera: Noctuidae). In Insect Pests of Cotton (G. A. Matthews and J. P. Tunstall eds.). CAB International, Cambridge, pp. 39-106.

Kyi, A., M. P. Zalucki and I. J. Titmarsh (1991) An experimental study of early stage survival of Helicoverpa armigera
(Lepidoptera: Noctuidae) on cotton. Bull. Entomol. Res. 81: 263-271.

Navasero, R. C. and S. B. Ramaswamy (1991) Morphology of leaf surface trichomes and its influence on egglaying by Heliothis virescens. Crop Sci. 31: 342-353.

Ramnath, S., K. Chitra and S. Uthamasamy (1992) Behavioural response of Helicoverpa armigera (Hübner) to certain host plants. J. Insect Sci. 5: 147-149.

Scriber, J. M. and F. Slansky (1981) The nutritional ecology of immature insects. Annu. Rev. Entomol. 26: 183-211.

Smith, C. W. (1992) History and status of host plant resistance in cotton to insects in the United States. In Advances in Agronomy, Vol. 48 (D. L. Sparks ed.). Academic Press, Sandiego, pp. 251-296.

Steel, R. G. D. and J. H. Torrie (1980) Principles and Procedures of Statistics. McGraw-Hill, New York. 633 pp.

Thompson, J. N. (1988) Evolutionary ecology of the relationship between oviposition preference and performance of offspring in phytophagous insects. Entomol. Exp. Appl. 47: 3-14

Thomson, N. J. (1987) Host plant resistance in cotton. Aust. J. Agric. Sci. 53: 262-270.

Twine, P. H. (1971) Cannibalistic behavior of Heliothis armigera (Hübner). Qld Agric. J. 99: 520-522.

Twine, P. H. (1978) Effect of temperature on the development of larvae and pupae of the corn earworm, Heliothis armigera (Hübner) (Lepidoptera: Noctuidae). Qld J. Agric. Anim. Sci. 35: 23-28.

Twine, P. H., R. I. Kay and R. J. Lloyd (1983) Heliothis in sorghum. Qld Agric. J. 109: 185-188.

Udayagiri, S. and C. E. Mason (1995) Host plant constituents as oviposition stimulants for a generalist herbivore: European corn borer. Entomol. Exp. Appl. 76: 59-65.

Van den Berg, H., B. T. Nyambo and J. K. Waage (1990) Parasitism of Helicoverpa armigera (Lepidoptera: Noctuidae) in Tanzania: Analysis of parasitoid-crop associations. Environ. Entomol. 19: 1141-1145.

Walter, G. H. and M. D. Benfield (1994) Temporal host plant use in three polyphagous Heliothinae, with special reference to Helicoverpa punctigera (Wallengren) (Lepidoptera: Noctuidae). Aust. J. Ecol. 19: 458-465.

Wilson, L. T., A. P. Gutierrez and T. F. Leigh (1983) Within plant distribution of immatures of Helicoverpa zea on cotton. Hilgardia 48: 12-23.

Yoshimatsu, S. (1995) Outbreaks of Helicoverpa armigera (Hübner) in western Japan in 1994 and its host plants. Plant Protection 49: 495-499 (in Japanese).

Zalucki, M. P., G. Daglish, S. Firempong and P. H. Twine (1986) The biology and ecology of Heliothis armigera (Hübner) and $H$. punctigera Wallengren (Lepidoptera: Noctuidae) in Australia: What do we know? Aust. J. Zool. 34: 779-814.

Zalucki, M. P., D. A. H. Murray, P. C. Gregg, G. P. Fitt, P. H. Twine and C. Jones (1994) Ecology of Helicoverpa armigera (Hübner) and $H$. punctigera (Wallengren) in the inland of Australia: Larval sampling and host plant relationships during winter and spring. Aust. J. Zool. 42: 329-346. 